\title{
El estudio de las relaciones internacionales en China antigua: el Sistema tributario en la dinastía Ming
}

\author{
Eduardo Tzili Apango \\ Centro de Estudios de Asia y África \\ El Colegio de México \\ Itzel Martínez Ruiz \\ Centro de Estudios de Asia y África \\ El Colegio de México \\ TONATiuh Fierro de Jesús \\ Centro de Estudios de Asia y África \\ El Colegio de México
}

\begin{abstract}
Resumen
Los estudios sobre China, o Asia en general, ofrecen campos de investigación apropiados para la reformulación de teorías y paradigmas. Tal es el caso de la teoría del Sistema tributario, la cual ha explicado la historia de las relaciones internacionales de China durante medio siglo al menos. Básicamente, esta teoría afirma que las relaciones entre China y sus vecinos fueron de carácter tributario, en las que las dinastías chinas fungieron como receptoras de honores y tributos, mientras que los pueblos circundantes tuvieron que acatar esta dinámica. Sin embargo, recientes investigaciones apuntan a que este tipo de vínculos no fue la norma. Nuestro estudio se enfoca en las relaciones de la dinastía Ming con pueblos del norte y del sur-sureste. No pretendemos resolver cuestiones históricas, sino, más bien, fomentar preguntas de investigación que ahonden futuros académicos. Nuestra hipótesis es que las relaciones tributarias solo se dieron en el nivel de gobierno mientras en el nivel de sociedad funcionó otro tipo de dinámica. Nuestra investigación nos lleva a concluir que, al menos durante Ming, las relaciones tributarias tuvieron auge y caída, pero las relaciones sociales se mantuvieron pese a la inexistencia de relaciones tributarias.
\end{abstract}

Palabras claves: Sistema tributario, relaciones internacionales, fronteras, China, dinastía Ming 


\begin{abstract}
Chinese studies, or Asian studies in general, offer appropriate research fields for reformulating certain theories or paradigms. Such is the case of the Theory of the Tributary System, which has explained China's history of international relations for nearly half a century. Basically, this theory affirms that relations between China and its neighbors were tributary in character. These Chinese dynasties were the objectives of given tributes and honors, while surrounding nations had to abide to this dynamic. However, recent research shows that these kind of social linkages were not the norm. Our paper focuses in Ming's dynasty relations with nations in the north and in the south-southeast. We will not attempt to solve historical questions, but to encourage research questions that future scholars will solve. Our hypothesis is that tributary relations were only at the government's level, whilst concerning the societal level another type of dynamics operated. Our research leads us to conclude that during the Ming dynasty, tributary relations had boom and bust, but social relations were maintained although no tributary relations existed at all.
\end{abstract}

Key words: Tributary System, international relations, borders, China, Ming dinasty

\section{Introducción}

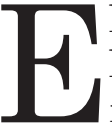
1 estudio de la historia de las interacciones humanas mantiene un vicio heredado de la escuela estadunidense de Relaciones Internacionales: considerar el Estado como un hecho histórico y estático que desde las primeras civilizaciones al presente no ha cambiado sustancialmente. Sin describir todo el desarrollo del debate interparadigmático en la disciplina (Sodupe), solo cabe destacar que hasta recientemente se ha optado por el término polities (organizaciones políticas) para caracterizar las unidades sociales que han mantenido relaciones desde las ciudadesestado sumerias.

En lo que concierne al este asiático, resaltan las aportaciones de Tin-bor ("Toward a Dynamic Theory of International Politics"; War and State Formation in Ancient China and Early
Modern Europe), Zhang y, sobre todo, Kang ("The theoretical rules of hierarchy in international relations"; China rising; "Hierarchy and Legitimacy in International Systems"). Estos estudios manejan el concepto de "Estado" como unidad analítica básica; dan por hecho que existieron Estados durante las dinastías chinas. Esta corriente inició con las contribuciones de Lattimore y Fairbank (The Chinese World Order), quienes realizaron estudios sobre la frontera y las relaciones político-culturales en las dinastías chinas y asumieron que China y sus vecinos fueron Estados.

Sin embargo, concordando con Romero ("Una perspectiva no eurocéntrica para el estudio de las relaciones internacionales"; "El estudio de Asia entre el Orientalismo y la diversidad cultural"), nosotros no coincidimos del todo con el paradigma existente. Pareciera que se ha forzado la teoría estatocéntrica de las Relaciones Internacionales 
para comprender la historia de las relaciones no europeas, lo cual es una posición eminentemente eurocéntrica. La teoría del Sistema tributario, que ha sido el paradigma dominante del estudio de las relaciones internacionales durante las dinastías chinas, maneja la idea del Estado como unidad principal de análisis. Nuestro estudio se enfoca en resaltar algunos hechos durante la dinastía Ming que bien podrían hacer repensar esta posición. Escogimos la dinastía Ming porque algunos autores concuerdan en que el Sistema tributario funcionó con todo su esplendor durante esta época (Andornino; Botton).

Nuestro artículo se divide en tres partes. En la primera describimos la teoría del Sistema tributario. En la segunda parte, contrastamos dicha teoría con algunos hechos históricos de las relaciones entre la dinastía Ming y pueblos circundantes. Finalizamos con una serie de consideraciones finales y propuestas para futuras líneas de investigación.

\section{El Sistema tributario en teoría}

El Sistema de tributos dio inicio a las primeras relaciones de China con sus vecinos y estableció un conjunto de instituciones, normas sociales y diplomáticas que dominaron las relaciones de China con el mundo no chino desde la dinastía Han (206 a.e.c.-220 e.c.) hasta la caída de la dinastía Qing (1644- 1912). Si bien el tributo no siempre abarcó el comercio, o viceversa, en Ming temprano sí hubo una mayor relación entre ambos. Ya en la época Qing esta tendencia siguió cobrando fuerza con la penetración de las ideas liberales, principalmente en las zonas de tratados.
La visión del mundo para los chinos -"Todo bajo el Cielo" o Tianxia ${ }^{1}$ significó que el emperador era el Hijo del Cielo, el mediador entre el universo y todos los seres humanos, lo cual legitimaba su poder. China -el imperio central o Zhongguo- dictaminó las normas universales de la civilización. El concepto de Sistema tributario fue creado en Occidente para describir las relaciones que tenía China con su exterior. Este término fue ideado en el siglo XIX y traducido en chino como chaogong tizhi (Zhang). Estrictamente hablando, el Estado chino no fue un Estado-nación al estilo europeo, sino una administración de la sociedad civilizada en su totalidad. El emperador, lejos de ser el gobernante de un Estado, fungió como el mediador entre el Cielo y la Tierra, el ápice de la civilización, el único en el universo (Mancall 63).

La filosofía confuciana fue la base de este orden jerárquico; tuvo el apoyo de la élite letrada mediante doctrinas de supraordenación - subordinación, las cuales regularon las relaciones de soberano a súbdito, de padre a hijo, de marido a mujer, de hermano mayor a hermano menor y de amigo a amigo. Como argumenta Mancall (63), "en el plano de la filosofía social, la relación tributaria se concibió como una ampliación de la estructura social de la civilización en los reinos más allá del poder inmediato del emperador." Estas relaciones reflejaron la estructura social china, considerada como una extensión de la familia. También constituyeron la forma en que funcionó y estructuró el Sistema tributario.

La presentación del tributo al emperador fue el ritual adecuado para reconocer el orden mundial sinocéntrico (Mancall 64). El tributo consistió 
en la presentación de productos nativos, una ofrenda simbólica de los frutos del país afluente. El valor de los objetos fue equilibrado. El tributo fue un signo de respeto, lealtad, reconocimiento de autoridad y una forma de expresar gratitud por la benevolente protección del emperador. El Sistema tributario fue un medio diplomático, el vehículo de las relaciones exteriores de China. Cada vez que un nuevo gobernante ascendió al trono de algún Estado tributario, fue requerido por los reglamentos de la corte imperial (Fairbank, "Tributary Trade and China's Relations with the West" 135), con la finalidad de que el nuevo gobernante se sujetara a las normas del imperio central. De igual manera, la concepción de la relación tributaria, como una ampliación de la estructura social de la civilización en los pueblos más allá del poder inmediato del emperador (Mancall 65), no estuvo exenta de desacuerdos y resistencia a su asimilación.

El embajador sólo fue un mensajero; su persona no fue inviolable y pudo ser tratado con dureza (Mancall 65). El dirigente de la misión era recibido en la residencia oficial de los enviados tributarios, donde pagaban para el mantenimiento de los hombres y los animales. En su ir y venir iban acompañados por tropas para su protección y vigilancia. Cuando se presentaron frente al emperador debían hacer el koutou, especie de reverencia que consistió en ponerse de rodillas y tocar el suelo con la frente tres veces. A la misión se le ofrecieron, varias veces, banquetes en presencia del emperador. Un enviado que muriera en el imperio recibía honores confucianos inusuales: un ensayo funeral era recitado y quemado en su tumba, se hacían ofrendas de sacrificio, y se colocaba una piedra encima de ella con una inscripción imperial (Fairbank, "Tributary Trade and China's Relations with the West" 133-135). El koutou significó el respeto y buena fe a las relaciones familiares y sociales, y el más solemne acto al emperador, de ahí su gran importancia. Este ritual diplomático significó el establecimiento de normas de reconocimiento, negociación política, solución de controversias, ayuda económica o militar, entre otras.

De acuerdo con Zhang (571), la construcción del Sistema tributario tuvo dos metas principales: legitimidad y seguridad. Sin importar si el gobierno chino fuera fuerte o débil hubo que cumplir estas dos metas, sobre todo la primera. Empero, para Zhou (177), el objetivo del Sistema tributario no sólo fue obtener legitimidad, sino algo más profundo, la seguridad y estabilidad en las regiones fronterizas. La legitimidad del Sistema tributario antes de la incursión de los occidentales fue incuestionable, por el dinamismo armónico entre China y sus tributarios. En el transcurso del siglo XIX, el Sistema tributario en la dinastía Qing se volvió menos acorde con la realidad china y de los pueblos tributarios. A medida que el país se empobreció por la falta de apoyo al campo, la corrupción casi institucionalizada, y que Occidente controló más territorio chino, surgió la ilegitimidad imperial que impidió a China influir sobre sus tributarios.

Zhang y Buzan argumentan que el surgimiento del Sistema tributario como orden internacional implicó tres elementos importantes. En primer lugar, el Sistema tributario articuló las ideas de un orden cósmico-social bajo una idea universal, centrado en la 
civilización china, y de un orden moral y político incluyente, presidido por el emperador chino como la encarnación de la bondad y la virtud. En segundo lugar, este orden moral, social y político, no fue culturalmente excluyente. Tuvo el propósito de incorporar a los pueblos con herencia cultural similar y una cosmovisión confuciana compartida. Al mismo tiempo, estuvo abierto a la participación de grupos diferentes, ya sea por medio de la persuasión o la fuerza. La China imperial actuó como un poder hegemónico más que como un soberano, por medio de su autoridad moral y su poder material. Sólo así pudo mantener el Sistema tributario.

Después de algún tiempo de turbulencia, en las dinastías Ming y Qing se restauró el orden cósmico confuciano, y la idea de superioridad continuó. Los chinos creyeron que el Sistema tributario, como institución, debía "equilibrar" la estabilidad interna (neiwen) con la estabilidad externa (waiwen). La "estabilidad interna" de China sólo podría lograrse si había "estabilidad externa" en su periferia, y el entorno externo de China sólo podría estabilizarse si había "estabilidad interna" (Saw 326). Al respecto, Zhang (553) sostiene que el Sistema tributario mantuvo y aseguró la cooperación de China y sus súbditos en el marco de la Pax sínica.

El Sistema tributario fue una extensión del poder político nacional chino. La agitación interna en un pueblo tributario pudo resultar en el colapso de la autoridad central (Cheng 11). La función del emperador fue mantener la armonía, por lo que el sentido ético y moral tomó un sentido más amplio en el actuar del Imperio.

Desde la dinastía Han, el lenguaje, los rituales y los cánones confucianos sobre la concepción del mundo se pusieron en práctica. La actitud de superioridad reflejada en el Sistema tributario se desarrolló durante un período largo como producto de la historia y no como un rasgo inherente de los chinos (Cheng 11). La idea de superioridad se ve desde un enfoque cultural y no racial, los "bárbaros" por medio de la educación confuciana podrían "civilizarse" o asimilarse. El regreso al orden cósmico confuciano parece que tuvo más relación con los intereses y objetivos personales del emperador y con los intereses de algunos grupos comerciantes. El imperio chino implementó la idea de imparcialidad y esta constituyó la proyección del poder chino hacia el exterior. Esta idea surgió porque China no pudo ser desafiada al contar con una gran fuerza y organización militar, pero sin un poder estrictamente ofensivo.

El Sistema tributario funcionó mejor en la conducción de las relaciones con los pueblos pequeños y remotos. Este sistema no sólo implicó deberes, sino también incluyó obligaciones paternalistas de China hacia ellos. $\mathrm{Cu}$ ando las relaciones tributarias se ampliaron, el sistema entró en un estado de equilibrio delicado, susceptible a los cambios políticos, económicos y militares de sus integrantes. La expansión de China no implicó el aniquilamiento de las poblaciones.

A mediados del siglo XIX, según Fairbank ("The Early Treaty System in the Chinese World Order" 257-258), pese al surgimiento de una nueva era en la que las ideas liberales -modernización, nacionalismo y revolución- se hicieron presentes, principalmente en la élite educada china, el sistema tradicional no se rompió de inmediato. 
De hecho, hasta 1894, las relaciones tributarias de China parecieron no tener ningún cambio. Pueblos como Choson, Ryuku, Vietnam, Myanmar, Laos, Tailandia, Filipinas, Nepal, Uzbekistán y Pakistán mantuvieron su relación tributaria (Quan 17). Incluso, Nepal tuvo una misión final en 1908. De 1843 hasta 1880 se reportaron 83 misiones. Pese a la negación de los occidentales de establecer una relación ritualista, o jerárquica, con el imperio, y al impulso de que sus relaciones fueran entre iguales, las misiones tributarias del este de Asia todavía realizaron el koutou (Fairbank, The Chinese World Order 263 y 266). La bifurcación del Sistema tributario y la emergencia de la diplomacia china convergieron porque las ideas confucianas y la concepción del Tianxia estaban arraigadas en el imaginario estatal y social y permeadas en la estructura china. Así, no hubo personal calificado para el manejo de las relaciones diplomáticas. Se preparó el terreno para su inserción en el escenario internacional.

\section{El Sistema tributario durante la di- nastía Ming}

Ya describimos lo que, en teoría, fue el Sistema tributario. Este concepto ha sido paradigmático en el estudio de la historia de las relaciones internacionales del este asiático. Sin embargo, ¿realmente fue así? Es decir, ¿un sistema pudo haber funcionado de esa manera? Si no, entonces ¿de qué manera? Estas son las preguntas de investigación de este apartado.

Entender el curso de la historia china implica analizar las características y sucesos internos y externos. Emitir un juicio sobre las relaciones de China con el exterior presupone un amplio conocimiento de los acontecimientos dentro y fuera del país, sobre todo porque la interacción con el exterior influyó significativamente en la organización social, política y económica, además de determinar la construcción de una identidad.

Hay, por un lado, la tendencia de observar las relaciones históricas en el este asiático de manera eurocéntrica. Esto implica aceptar el "Estado" como base analítica. Por otro lado, hay la tendencia de observar las relaciones de manera sinocéntrica, lo que implica aceptar un orden jerárquico con base en la subordinación al tianzi (emperador) y la práctica de ritos.

La primera tendencia ha resultado en la formulación de la Teoría del Sistema Internacional Jerárquico, la cual establece un orden de Estados por rango. La hegemonía es una forma de jerarquía que, además de capacidades materiales, toma en cuenta una gama de normas (orden social) que Estados secundarios legitiman; más que un orden internacional es un "orden social" (Kang, "Hierarchy and Legitimacy in International Systems" 598). La segunda tendencia ha resultado en la formulación de la Teoría del Tianxia, que establece un orden por medio del seguimiento de relaciones e instituciones sociales. La armonía representa una meta social final y resulta ser una filosofía para la gobernabilidad global (Hückel 43; Qin 80; Zhao). La primera tendencia es analítico-descriptiva y la segunda es normativa.

El establecimiento de pueblos en la frontera norte de China, desde épocas muy remotas, les otorgó un lugar muy importante en la historia y desarrollo 
de la civilización. Desde la antigüedad, el pueblo chino y los nómadas establecieron relaciones, las cuales, dependiendo de la época y características sociales y políticas, se desenvolvieron de manera distinta. A través de la historia los chinos y los nómadas fueron adversarios militares, aliados políticos y socios comerciales (Rossabi, "The Ming and Inner Asia” 224).

Tradicionalmente, el imperio chino se consideró el centro del mundo y conservó un sentimiento de unidad y continuidad como civilización. Los grupos que se establecieron en su periferia fueron considerados inferiores ya que no compartieron lazos de parentesco y mostraron evidentes diferencias en su estilo de vida. Una razón fue la diferencia entre las actividades que desarrollaron, como el pastoreo, la cacería, la pesca y el comercio, actividades poco aceptadas en el imaginario chino (Di Cosmo, "Ancient Inner Asian Nomads" 2).

Desde una visión sinocéntrica, es casi imposible suponer que las tribus nómadas contribuyeron en la construcción de la identidad cultural china debido a que eran considerados como gente no civilizada, agresiva, codiciosa y voraz. Para los chinos, estos grupos no compartían las características civilizadoras de la dinastía Zhou, y se referían a los Rong y a los $D i$ (grupos nómadas del norte) como una especie de lobos agresivos y crueles, personas insaciables que se movían en búsqueda de tierras fértiles y agua (Di Cosmo, "Ancient Inner Asian Nomads" 3-5). ${ }^{2}$ Además, dentro del idioma chino fueron tomadas en cuanto las peculiaridades raciales, culturales y étnicas para identificar a una persona china. Zhongguoren, zhongyuan, zhonghua minzu, huaren, huaqiao, tangren y hanren fueron algunos de los conceptos empleados para indicar que un individuo formaba parte de la comunidad; su uso varió dependiendo de la zona y el grupo social que los utilizaba y la época (Yenho 159-179).

El desarrollo del territorio en el norte permitió la construcción de rutas y vías de comunicación por medio de las cuales fluyeron, hacia China, ideas, conocimientos, bienes y creencias de esos pueblos. Según Di Cosmo ("Ancient Inner Asian Nomads"), las comunidades del norte brotaron en la oscuridad prehistórica y su historia puede ser reconstruida a partir de las menciones de su participación en batallas o alianzas que forjaron con familias del norte de China.

La expansión del imperio chino desplazó a los pueblos nómadas hacia el norte, en donde el clima se caracterizaba por temperaturas extremas, y el terreno por su aridez y escasez de agua, lo que limitó el desarrollo de la agricultura. Algunas teorías señalan que, antes de la expansión del imperio chino, las comunidades del norte fueron semiagrícolas. Pero, poco a poco, se fueron transformando en comunidades totalmente pastoras y cazadoras; en estas actividades encontraron una forma de subsistir. Los pueblos nómadas también se caracterizaron por el desarrollo del hierro y bronce muy avanzado para su época. Fabricaron armas, herramientas, utensilios, espejos, vasijas de bronce, cuchillos, entre otros, y fueron pioneros en el desarrollo de tecnología muy especializada para domar a los caballos como cinturones y arneses (Di Cosmo, "Ancient Inner Asian Nomads" 1093).

Los pueblos de la frontera norte de China nunca consiguieron constituir 
una economía de subsistencia dadas las condiciones atmosféricas y las características del suelo. Por medio del comercio o del saqueo a pueblos chinos, los nómadas lograron conseguir productos para sobrevivir, tales como granos, textiles, herramientas (Serruys, "SinoMongol Trade During the Ming" 34).

La dependencia de los grupos nómadas de los productos chinos propició problemas e inestabilidad en la zona. A medida en que las familias chinas comerciaron con grupos nómadas, y les suministraron los bienes que necesitaron, la relación entre ambos fue pacífica, pero cuando se les cerró el comercio, los grupos nómadas fueron orillados a cometer asaltos, atracos e incluso guerras para poder obtener los recursos y satisfacer sus necesidades. Debido a su condición de poblaciones nómadas, adquirieron una gran destreza para cabalgar, aprovecharon sus habilidades de caza en el área militar y sus condiciones de vida los hicieron organizarse en pequeños ejércitos para protegerse mutuamente, convirtiéndose así en grandes y poderosos guerreros (Di Cosmo, Ancient China and Its Enemies 42).

Los grupos nómadas no fueron los únicos que se beneficiaron del comercio con China, también los chinos se favorecieron de estas relaciones comerciales. El primer beneficio que obtuvieron los chinos fue el caballo; los pueblos del norte domesticaron bastante bien estos animales, fabricaron el equipo y las herramientas para manejarlos y descubrieron diferentes tácticas para cabalgar. Los chinos supieron aprovechar la domesticación del caballo para desplazarse fácilmente en el campo y los ejércitos. Además, desde Asia central se introdujo en China la cuadriga, que fue indispensable para la guerra. Los chinos también se beneficiaron de la adquisición de nuevas tácticas de guerra, avances en la metalurgia, la introducción y manejo de nuevas armas (Di Cosmo, "Ancient Inner Asian Nomads" 945-949).

El problema de la vigilancia y dominio de la frontera norte siempre preocupó al gobierno dinástico chino. Este tema se convirtió en un asunto de seguridad porque la región fue vulnerable debido a la presencia de múltiples grupos nómadas poderosos, que en más de una ocasión se hicieron del control de la zona. La conquista de los mongoles fue la más significativa, ya que, por primera vez, China estuvo sometida en su totalidad ante un gobierno extranjero completamente opuesto al ideal chino, subyugada por un pueblo que los chinos consideraban inferior.

Cuando la dinastía Yuan cayó y los chinos retomaron el poder, el país atravesó por un momento de reorganización social, política y económica. Aunque esta dinastía solo duró cien años, no fue fácil para los chinos romper relaciones con los mongoles. Antes de la dominación mongola existieron numerosos vínculos comerciales, políticos y sociales que se fortalecieron durante la dinastía Yuan, por lo que no fue conveniente concluir la relación.

Por miedo a ser invadido y dominado nuevamente, por el riesgo de ataques militares para recuperar el poder, o simplemente por orgullo, pensaríamos que el gobierno Ming restringió totalmente cualquier tipo de contacto entre el pueblo chino y el mongol. Sin embargo, las relaciones con los mongoles nunca desaparecieron, los lazos comerciales, políticos y sociales que los unían eran fuertes, y ambas partes se 
beneficiaban de su relación con el otro. Los mongoles que vivieron en la frontera norte adoptaron el estilo de vida chino, aunque no del todo. Copiaron algunas costumbres como la agricultura y la vida sedentaria, e inclusive buscaron nombres chinos. Otros se incorporaron en las filas del ejército chino. ${ }^{3}$

La cantidad de mongoles, de jurchen y de población de Asia Central que estuvo concentrada en la frontera norte (actuales provincias de Hebei, Shandong, Shanxi, Gansu y Liaodong), preocupó a los oficiales chinos, quienes tomaron medidas para controlar su avance (Serruys, "The Mongols in China" 233-236). En los anales de la dinastía Ming, Rossabi ("Two Ming envoys to Inner Asia” 9) encontró documentos que muestran la existencia de enviados especiales chinos, quienes se establecieron en territorios mongoles con fines políticos o económicos. Estos hombres aprendieron el idioma y las costumbres extranjeras, las entendieron y supieron sacar provecho de sus conocimientos, facilitaron y mejoraron las relaciones con los líderes de esa zona, conocieron sus planes y permitieron que los gobernantes chinos estuvieran preparados ante cualquier situación que pusiera en riesgo su gobierno.

Otra de las estrategias implementada fue la incorporación de mongoles en los ejércitos chinos o en la policía. $\mathrm{Al}$ estar al servicio del gobierno, se les proporcionó comida, casa, muebles, regalos, salarios (eran calculados en granos de arroz), tierras (utilizadas para el pastoreo, crianza de caballos y en pocos casos, agricultura) y se les eximió de pagar impuestos (Serruys, "The Mongols in China" 255-266). Los gobernantes pensaban que cuando los mongoles buscaron el apoyo de los chi- nos se sentían débiles, y cuando se sentían fuertes violaron las fronteras, por eso prefirieron ayudarlos para ganarse su lealtad y vigilarlos.

El establecimiento de la dinastía Ming restauró el comercio tributario. A pesar de que el gobierno supo que el comercio no conllevó grandes beneficios económicos, lo empleó porque sirvió para expandir su poder e influencia. China fue económicamente autosuficiente, por eso se aprovechó de la demanda de productos por parte de los nómadas para emplear el comercio como recurso político, no económico (Rossabi, "The Tea and Horse Trade with Inner Asia During the Ming" 136). También fue útil para evitar la invasión de los nómadas, quienes en busca de productos para sobrevivir incidieron en múltiples ocasiones en conflictos bélicos, robos y/o comercio clandestino. Lo anterior ocurrió, sobre todo, cuando el comercio estuvo cerrado, o las alianzas entre ellos se rompieron y no pudieron intercambiar artículos.

Los chinos establecieron relaciones comerciales con los mongoles por medio de tres modalidades. La primera como parte del Sistema tributario (se construyeron varias embajadas). La segunda con la construcción de centros de venta en las principales ciudades chinas (como el famoso palacio Huitong Guan, en Beijing). La tercera con la apertura de mercados en las fronteras regulados por el gobierno (Serruys, "The Mongols in China" 38).

A pesar del poco interés que el gobierno chino mostró por el comercio con los mongoles, obtuvo muchos productos gracias a esta actividad. Adquirieron caballos, ovejas, carne, pelo de caballo, ganado, lana y pelajes de animales como martas cibelinas, armiños, 
zorros, leopardos, osos, tigres, venados, linces, nutrias y ardillas; ginseng, cera, miel, hongos, madera de pino y armas. Los mongoles compraron bueyes, herramientas para la agricultura y el arado, semillas, tiendas de campaña, teteras, jarrones de cobre, sillas para caballos, bridas, tijeras, arado, papel, medicinas, yunque, tenacillas, arroz, agujas y dagas.

Mientras los mongoles dominaron el territorio chino, mantuvieron lazos muy fuertes con su cultura nómada. El proceso de sinización fue muy lento, y en muchos casos nulo. Como parte de su estrategia, el gobierno mongol adoptó la forma de organización política y las instituciones chinas, que siguieron vigentes durante el periodo de Ming.

Instituciones y costumbres mongolas sobrevivieron a la caída de la dinastía Yuan, tales como la forma de organización del ejército, los puestos militares hereditarios, la guardia imperial y el Departamento Imperial Musulmán de Astronomía. Varias palabras mongolas se añadieron al vocabulario chino, se preservaron estilos de vestimenta, el uso de nombres y títulos, la cremación de los muertos, las formas de saludar; ceremonias y ritos matrimoniales, entre otras. Sin embargo, al gobierno chino no le gustó que prevalecieran estas costumbres porque iban en contra del confucianismo y gradualmente las modificó por medio de leyes (Serruys, "Remains of Mongol Customs in China During the Early Ming Period" 139-171).

Las dinastías chinas ya habían practicado ciertas instituciones del sistema internacional europeo, aunque no definieron China como Estado-nación. La firma de tratados es un ejemplo claro. En 1005, las dinastías Song del sur y Liao de los Kitanes firmaron el Tratado de Shanyuan. En éste se estipuló el pago anual de 100000 taeles y 200000 piezas de seda, por parte de Song, para mantener la paz y las relaciones amistosas. Este evento recuerda la misma táctica por parte de la dinastía Han para "comprar" la paz con los Xiongnu, o los acuerdos que se firmaron entre la dinastía Tang y los reinos tibetanos. El Tratado de Shanyuan estableció un modelo de interacciones que siguieron los pueblos del este asiático desde el siglo IX al XIII. Reconoció a dos tianzi, por lo que, también, reconoció la igualdad entre las partes (Yun 141-142).

La imposición europea a China no consistió en regulaciones diplomáticas, sino en demarcaciones fronterizas. La transición intersistema no debió haber sido tan dramática en razón de prácticas diplomáticas similares a las europeas. Pero lo fue porque China se vio forzada a reconocer límites a su influencia cultural, política y económica. Esto, a su vez, desarrolló un nacionalismo, necesario para todo Estado-nación.

Históricamente, la única frontera que China delimitó, aunque parcialmente, se ubicó en el norte. El poder de los Xiongnu, durante la dinastía Han, obligó a definir límites territoriales de influencia. Más allá de la visión maniquea de que los Xiongnu fueron un pueblo nómada y los Han un pueblo sedentario, lo que se observa es la existencia de pueblos seminómadas a lo largo de la "frontera". Estos pueblos practicaron la caza y una agricultura rudimentaria, además de que sirvieron como enlaces comerciales (Di Cosmo, "Ancient Inner Asian Nomads"; Yü 9 y 16). Por ello, la frontera no maduró por completo. El movimiento confuciano, en la burocracia de la dinastía Yuan, no solo se 
extendió pese a las diferencias regionales en China, sino que también cruzó fronteras étnicas y amplió su membresía entre grupos mongoles y gente de Asia central, ya que no demandó "sinificación” para la admisión. El enfoque confuciano promovió ir más allá de la escisión étnica, por lo que, probablemente, fue más asequible al extranjero (Dardess 33-34). El comercio y la cultura, pues, sirvieron como elementos amalgamadores, no excluyentes.

Para cuando se estableció la dinastía Ming (1368-1644 e.c.), recuperar China no significó abandonar la estepa a los mongoles, ya que se estableció el gobierno y el aparato militar con base en modelos Yuan, además de que el primer emperador de Ming intentó mantener un control conjunto de China y la estepa (Smith y Glahn 82). Los nuevos significados que se agregaron a zhongguo le impidieron, por ejemplo, regresar a la estructura política y cultural de Song, ya que se amplió, se enriqueció y se modificó. En aquel momento abarcó desde Corea en el este, hasta Tíbet en el oeste, y Daqi en el norte, hasta Anam en el sur, como se reconoce en Mingshi ("Historia de la dinastía Ming").

De acuerdo con Botton (312-313), la dinastía Ming volvió a conceder gran importancia al Sistema tributario como un intento por "realizar el orden cósmico confuciano, en el cual el tianzi controla, sin grandes prerrogativas ni restricciones, a sus vasallos". Así, el emperador Hongwu envió misiones a Corea, Japón, Anam, Champa, Tíbet, entre otros, con la petición de que se le reconociera como soberano legítimo de Tianxia. Estos pueblos, además de Java, algunas regiones de Indochina y Asia Central, las islas
Liuqiu, India, Malaya, Borneo, Sumatra y hasta Siria, respondieron con el envío de emisarios.

En este sentido, el tributo fue un símbolo de sumisión al orden esteasiático y el refuerzo del estatus superior de China, más que transferencias económicas que beneficiaran a una parte. Ming subyugó a casi todas las organizaciones políticas importantes de Yunnan para 1444, y durante veintiún años intentaron someter a Vietnam ${ }^{4}$. Los viajes de Zheng He se iniciaron por Ming para estimular el comercio tributario y anunciar la preeminencia regional china (Gunn 104 y 127).

Contrario a lo anterior, Elvin (217218) establece que durante gran parte de la dinastía Ming se redujo el crecimiento económico que se experimentó durante Tang y Song, lo cual se relaciona con la política gubernamental de reducir el contacto entre China y el mundo exterior. Esta política, si bien varió a través del tiempo, definió fronteras a manera de control administrativo. Por ejemplo, en 1371 se prohibió a la gente de la costa de Fujian y Zhejiang mantener comunicación con gente del exterior, con quienes comerciaban; en 1394 se prohibió el uso de bienes extranjeros; en 1397 se estableció que las únicas embarcaciones con las que se podía comerciar eran aquéllas que fuesen misiones oficiales tributarias; en 1407, después de la anexión de Anam, se prohibió a civiles y militares cruzar la frontera para comerciar con países lejanos.

Durante un breve tiempo se relajaron las restricciones, pero volvieron a imponerse en el siglo XVIII: prohibición de hacer viajes privados al extranjero, edicto de 1717, prohibición de vivir en el extranjero, en 1727, y formalización de Cantón como único 
puerto legal para el comercio exterior, en 1757.

A pesar del relativo aislamiento, la "expresión defensiva del culturalismo", con base en la extensión de la dinámica social confuciana en la relación con otros pueblos, fortaleció el orden en el este asiático y de instituciones "típicas" de relaciones interestatales, como vínculos diplomáticos, repatriación y extradición de personas y regulación del comercio exterior. Aquellos gobernantes no chinos, en su deseo de contactar a China y establecer un comercio de gran valor, tenían que pagar el precio de las formalidades "tributarias" o, más bien, confucianas (Fairbank, Reischauer y Craig 195).

En el norte y oeste de China, el sistema funcionó como instrumento de defensa y diplomacia, mientras que en el sur y oriente funcionó como regulador de comercio exterior e institución flexible que combinó diplomacia, defensa y ventajas comerciales. También reconoce que el sistema de comercio tributario evolucionó a través del tiempo. Varios miembros se salieron, otros ingresaron, algunos permanecieron leales, otros invariables, e incluso algunos, como Japón y Vietnam, intentaron formar sus propios sistemas tributarios (Gunn 130).

Si bien la dinastía Ming mostró gran poder marítimo en la región, no se convirtió en una potencia naval. Esto se debe a que el neoconfucianismo retomó el clásico rechazo al comercio, lo que inhibió el desarrollo de una flota mercantil y militar de gran envergadura. Las relaciones de Ming con sus vecinos se basaron en rituales confucianos que promovieron, paradójicamente, el comercio exterior. La fortaleza económica de Ming, que se observa por me- dio del aumento de la población, del área cultivada, del volumen de comercio internacional, en la producción de bienes industriales y en el uso de papel moneda, muestra el aumento de una integración más profunda, con base en relaciones culturales, entre China y sus vecinos (Gunn 199-204; Fairbank, Reischauer y Craig 199-204). Es decir, el confucianismo como institución regional fortaleció la estructura del sistema del este asiático.

Schottenhammer ("The East Asian "Mediterranean" 123-126) considera que existió una compleja red de vínculos en las sociedades asiáticas, sobre todo en las costas del este y sureste asiáticos. Esto ocurrió de manera paralela a las relaciones "tributarias" que hacían los gobiernos y líderes. Por ejemplo, se observan los casos de los viajes de monjes budistas japoneses hacia China, o de físicos-médicos chinos hacia Japón, quienes no tuvieron que realizar el ritual confuciano que implicó el tributo, y son reflejo de la activa dinámica que existió entre las sociedades asiáticas.

Otro caso son las relaciones privadas y oficiales que se realizaron entre Ming y las islas Liuqiu (o Ryukyus), a las que, oficialmente, se les consideró como un fiel tributario de China. Sin embargo, las actividades comerciales privadas lograron salirse de las restricciones que implicó la monopolización del comercio entre Ming y las Liuqiu. Estas se pudieron realizar gracias a la formación de una clase de intermediarios, privados y oficiales, a cargo de gestionar el comercio. Más que monopolio, fue delegación de responsabilidades administrativas. Además, se considera también que las Liuqiu fueron intermediarias en el comercio entre Siam, Java y Malaca, por un lado, y China, 
por el otro (Shottenhammer, "Corredores y 'Gremios”' 580-581).

\section{Consideraciones finales}

El Sistema tributario fue un tipo de dinámica que solo se dio entre las élites gobernantes; el emperador de la dinastía, los embajadores y los reyes fueron sus protagonistas. Al menos durante Ming, hay registros de numerosos intercambios, acercamientos y vínculos de carácter no oficial que se dieron aún con las intenciones del gobierno Ming de reducir la salida de sus súbditos al exterior.

Como ya describimos, en el norte tuvo lugar un fluido intercambio comercial. El hecho de que los mongoles dominaran China durante un siglo, no implicó que los chinos Ming redujeran sus interacciones con ellos. En todo caso, se formó una interdependencia entre los pueblos de las estepas norteñas y de las planicies sureñas. Como establecen Smith y Glahn (82), recuperar China no significó abandonar la estepa a los mongoles, ya que se estableció el gobierno y el aparato militar con base en modelos de la dinastía Yuan, además de que el primer emperador de Ming intentó mantener un control conjunto de China y la estepa. En el sur la historia es más compleja. Al ser la puerta hacia el este y sureste asiático, las costas chinas mantuvieron un flujo no solo comercial, sino social con base en los viajes de marineros, académicos y monjes. También hubo otro tipo de actividades como la piratería, que surgió al margen de las normas oficiales y que, al ser el modus vivendi de mucha gente, nunca desapareció en la historia de esta parte de China (Folch 267-
268). Es por esto que los misioneros occidentales, cuando llegaron a China, no tuvieron que cumplir las formalidades del Sistema tributario hasta que se entrevistaron con funcionarios del gobierno dinástico.

Si las relaciones entre los pueblos del este de Asia no fueron estrictamente tributarias, entonces ¿cómo podríamos caracterizarlas? Esto es tarea de futuras investigaciones. ${ }^{5}$ La dificultad en este tipo de investigación reside en la consulta de fuentes primarias, ya que la mayoría está en chino clásico y lenguas de difícil acceso (tangutano, mongol, manchú, japonés clásico, etc.). El reto es grande, pero es importante para los estudiosos de las relaciones internacionales atender este tipo de problemáticas, ya que así podremos comprender la dinámica global de mejor manera.

\section{Notas}

1. Para efectos de este trabajo utilizamos el sistema de transliteración pinyin, y excluimos los acentos tonales.

2. En un apartado del Shanhaijing (el libro clásico de las montañas y los mares), además de describir la geografía y la cultura de los pueblos nómadas, se representa a los hombres nómadas como seres mitológicos, entes con cuerpos de animales tales como serpientes, con nueve cabezas y un solo ojo en el centro de la cara.

3. Se han encontrado listas de mongoles en los ejércitos cuyos nombres están en chino, pero significan toro, burro, caballo, los cuales hacen alusión a características mongolas.

4. Vietnam, por ejemplo, pasó diez siglos bajo control chino (de Han a Tang), y nueve siglos bajo gobierno autónomo, 
aunque dentro de la órbita cultural china y de comercio tributario, adoptó la institucionalidad del emperador, la burocracia, el sistema de exámenes, los clásicos confucianos y la escritura china (chu nom)

5. Afortunadamente ya existen numerosos esfuerzos en esta dirección. Véase: Crossroads (varios números).

\section{Bibliografía}

Andornino, Giovanni. The Nature and Linkages of China's Tributary System under the Ming and Qing Dynasties. Working Paper of the Global Economic History Netwok. London School of Economics, 2006, electrónico (disponible en: http:// eprints.lse.ac.uk/22470/).

Botton Beja, Flora. China. Su historia y cultura hasta 1800. México D.F.: Centro de Estudios de Asia y África-El Colegio de México, 2000, impreso.

Cheng Weiching. War, Trade and Piracy in the China Seas, 1622-1683. Países Bajos: Brill y Leiden University, 2013, impreso.

Crossroads. Studies of the History of Exchange Relations in the East Asian World (http://www.eacrh.net/ ojs/index.php/crossroads/index).

Dardess, John W. Conquerors and Confucians: aspects of political change in late Yüan China. Nueva York: Columbia University Press, 1973, impreso.

Di Cosmo, Nicola. "Ancient Inner Asian Nomads: Their Economic Basis and its Significance in Chinese History". The Journal of Asian Studies, 1994, impreso.

Di Cosmo, Nicola. Ancient China and Its Enemies: The Rise of Nomad- ic Power in East Asian History. Cambridge: Cambridge University Press, 2000, impreso.

Elvin, Mark. The Pattern of the Chinese Past. California: Standford University Press, 1973, impreso.

Fairbank, John K. "Tributary Trade and China's Relations with the West". The Far Eastern Quarterly, 1942, impreso.

Fairbank, John K. The Chinese World Order. Traditional China's Foreign Relations. Cambridge, Harvard University Press, 1968, impreso.

Fairbank, John K. "The Early Treaty System in the Chinese World Order". En: Fairbank John, K. The Chinese World Order. Cambridge: Harvard University Press, 1968, impreso. Fairbank, John K., Reischauer, Edwin O. \& Craig, Albert M. East Asia Tradition and Transformation. Boston: Houghton Mifflin Company, 1973, impreso.

Folch, Dolors. "Piratas y flotas de China según los testimonios castellanos del siglo XVI". En: La Investigación sobre Asia Pacífico en España. Granada, España: CEIAP, Editorial Universidad de Granada, 2006, impreso.

Gunn, Geoffrey C. History without borders. The making of an Asian world region, 1000-1800. Hong Kong: Hong Kong University Press, 2011, impreso.

Hückel, Bettina. "Theory of International Relations with Chinese characteristics". Diskurs. 2013, electrónico (disponible en: http://www. diskurs-zeitschrift.de/2013/01/25/ theory-of-international-relationswith-chinese-characteristics-thetian-xia-system-from-a-metatheoretical-perspective/). 
Kang, David C. "The theoretical rules of hierarchy in international relations". Australian Journal of International Affairs. 2004, electrónico (disponible en: http://www.tandfonline.com/doi/abs/10.1080/10357710 42000260110? mobileUi=0\&journal Code=caji20\#.VRDKm_mG-So).

Kang, David C. China rising. Peace, power, and order in East Asia. Nueva York: Columbia University Press, 2007, impreso.

Kang, David C. "Hierarchy and Legitimacy in International Systems: The Tribute System in Early Modern Asia”. Security Studies. 2010, electrónico (disponible en: http://www. ingentaconnect.com/content/rout$\mathrm{ledg} / \mathrm{ss} / 2010 / 00000019 / 00000004 /$ art00001).

Lattimore, Owen. Inner Asian frontiers of China. Boston: Beacon Press, 1962, impreso.

Mancall, Mark. "The Ch'ing Tribute System: An Interpretative Essay". En Fairbank J. K. The Chinese World Order. Cambridge: Harvard University Press, 1968, impreso.

Qin Yaqing. "Desarrollo de la Teoría de Relaciones Internacionales en China”. Relaciones Internacionales. 2013, electrónico (Disponible en: http://www.relacionesinternacionales.info/ojs/article/view/440/331. html).

Quan Hexiu. "The Two Systems of Diplomacy of Late Qing China: External Relationship, Modernization and Transitional Phase". Journal of Northeast Asian History. 2008, electrónico (disponible en: http:// contents.nahf.or.kr/chinese/item/ level.do;jsessionid=D7CB87E3B90 D788903227A2760363CB7?levelId =jn_007e_0020\&langTypes $=$ c).
Romero Castilla, Alfredo. "Una perspectiva no eurocéntrica para el estudio de las relaciones internacionales: el este de Asia". Revista de Relaciones Internacionales de la UNAM. 2007, impreso.

Romero Castilla, Alfredo. "El estudio de Asia entre el Orientalismo y la diversidad cultural". Revista de Relaciones Internacionales de la UNAM. 2008.

Rossabi, Morris. "The Tea and Horse Trade with Inner Asia During the Ming". Journal of Asian History. 1970, impreso.

Rossabi, Morris. "Two Ming envoys to Inner Asia”. Toùng Pao: Second Series. 1976, impreso.

Rossabi, Morris. "The Ming and Inner Asia”. En Twitchett Dennis \& Mote Frederick (eds.). The Cambridge History of China Vol. 8. Nueva York: Cambridge University Press, 1998, impreso.

Saw Swee-Hock. ASEAN-China Economic Relations. Singapur: Institute of Southeast Asian Studies, 2007, impreso.

Schottenhammer, Angela. "Corredores y 'Gremios' (Huiguan會館) en el comercio marítimo de China con sus vecinos del este durante las dinastías Ming y Qing". Estudios de Asia y África. 2010, impreso.

Schottenhammer, Angela. "The East Asian 'Mediterranean': A Medium of Flourishing Exchange Relations and Interaction in the East Asian World". En Miller, Peter N. (ed.) The Sea: Thalassography and Historiography. Ann Arbor: The University of Michigan Press, 2013, impreso.

Serruys, Henry. "Remains of Mongol Customs in China During the Early 
Ming Period". Monumenta Serica. 1957, impreso.

Serruys, Henry. "The Mongols in China: 1400-1450". Monumenta Serica. 1960, impreso.

Serruys, Henry. "Sino-Mongol Trade During the Ming". Journal of Asian History. 1975, impreso.

Smith, Paul J., \& Glahn, Richard V. The Song-Yuan-Ming Transition in Chinese History, Cambridge: Harvard University Press, 2003, impreso.

Sodupe, Kepa. La teoría de las Relaciones Internacionales a comienzos del siglo XXI. España: Universidad del País Vasco, 2003, impreso.

Tin-bor Hui, Victoria. "Toward a Dynamic Theory of International Politics: Insights from Comparing Ancient China and Early Modern Europe”. International Organization. 2004, impreso.

Tin-bor Hui, Victoria. War and State Formation in Ancient China and Early Modern Europe. Nueva York: Cambridge University Press, 2005, impreso.

Yen-ho Wu, David. "The Construction of Chinese and Non-Chinese Identities". Doedalus, Journal of the American Academy of Arts and Sciences. 1991, electrónico (disponible en: http://www.jstor.org/discover/1 $0.2307 / 20025378$ ? sid=21105754159 491\&uid=3738664\&uid=4\&uid=2).

Yü Ying-shih. Trade and Expansion in Han China: A Study in the Structure of Sino-Barbarian Economic Relations. Berkeley, University of California Press, 1967, electrónico.

Yun, Peter. "Balance of Power in the $11^{\text {th }}-12^{\text {th }}$ Century East Asian Interstate Relations". Journal of Political Criticism. 2011, electrónico (disponible en: http://pol-commentary. org/wp-content/uploads/2012/11/6.$11-12 \% \mathrm{EC} \% 84 \% \mathrm{~B} 8 \% \mathrm{EA} \% \mathrm{~B} 8 \% \mathrm{~B} 0$ $\% \mathrm{~EB} \% 8 \mathrm{~F} \% 99 \% \mathrm{EC} \% 95 \% 84 \% \mathrm{EC} \%$ 8B\%9C\% EC\%95\%84-\% EA\%B5\% $\mathrm{AD} \% \mathrm{EC} \% \mathrm{~A} 0 \% 9 \mathrm{C} \% \mathrm{EA} \% \mathrm{~B} 4 \% 80 \%$ $\mathrm{EA} \% \mathrm{~B} 3 \% 84 \% \mathrm{EC} \% 97 \% 90 \% \mathrm{EC} \%$ $84 \% 9 \mathrm{C} \% \mathrm{EC} \% 9 \mathrm{D} \% 98-\% \mathrm{EC} \% 84 \%$ B8\% ЕB\%A0\%A5\%EA\%B $\%$ А $0 \%$ ED\%98\%954.pdf?ckattempt=1).

Zhang Feng. "Rethinking the 'Tribute System': Broadening the Conceptual Horizon of Historical East Asian Politics". Chinese Journal of International Politics, 2 (2009): 545-574. Oxford Journals. Web. 5 de diciembre de 2014. (http://cjip.oxfordjournals.org/content/2/4/545.extract).

Zhang Yongjin y Buzan, Barry. "The Tributary System as International Society in Theory and Practice". Chinese Journal of International Politics, 5 (2012): 3-36. Oxford Journals. Web. 5 de diciembre de 2014. (disponible en: http://cjip.oxfordjournals.org/content/5/1/3.extract).

Zhang Yongjin. "System, Empire and States in Chinese international relations". Review of International Studies, 27 (2001): 43-63. Cambridge Journals. Web. 5 de diciembre de 2014. (disponible en: http://journals. cambridge.org/action/displayAbstrac t?fromPage=online\&aid=163529).

Zhao Tingyang. Tianxia Tixi - Shijie Zhidu Zhexue Daolun (天下体系一 世界制度哲学导论). Nanjing, Jangsu Education Press, 2005, impreso.

Zhou Fangyin. "Equilibrium Analysis of the Tributary System". Chinese Journal of International Politics. 4 (2011): 147-178. Oxford Journals. Web. 5 de diciembre de 2014 (disponible en: http://cjip.oxfordjournals.org/content/4/2/147.extract). 